\title{
Mitochondrial DNA (mtDNA) and Cancer Pathogenesis - The Role of mtDNA Mutations: A Review
}

\section{Nikolaos Andreas Chrysanthakopoulos*}

*Correspondence: Nikolaos Andreas Chrysanthakopoulos

Address: Oncologist (MSc), Specialized in Clinical Oncology, Cytology and Histopathology, Department of Pathological Anatomy, Medical School, PhD in Oncology (cand), University of Athens, Greece

e-mail $\bowtie$ nikolaos_c@hotmail.com and nchrysant@med.uoa.gr

Received: 11 June 2021; Accepted: 18 June 2021

Copyright: (C) 2021 NA Chrysanthakopoulos. This is an open-access article distributed under the terms of the Creative Commons Attribution License, which permits unrestricted use, distribution, and reproduction in any medium, provided that the original work is properly cited.

\section{ABSTRACT}

Mitochondria are essential metabolic organelles as produce cellular energy by oxidative phosphorylation (OXPHOS), produce reactive oxygen species (ROS) as a by-product, and regulate functions such as apoptosis via the mitochondrial permeability transition pore (mtPTP). However, mitochondria are also responsible for multiple cellular functions such as, cellular development, growth, signals interaction from mitochondria to nucleus and nucleus to mitochondria, and are involved in miscellaneous metabolic pathways.

Those processes are accomplished by several protein complexes and mitochondrial respiratory chains (MRC) encoded by nuclear and mitochondrial DNA (mtDNA), as are assembled from both nuclear DNA (nDNA) and mitochondrial DNA genes. The mt DNA is a circular, double-stranded molecule 16,569 base pairs (bp) in length, contains 37 genes which code 13 polypeptides, 2 genes of rRNA $(12 S, 16 S)$, and 22 genes of tRNA, and is present in thousands of copies in each human cell. Almost 90 years ago, Otto Warburg hypothesized that a defect in energy metabolism is the initial cause of cancer. Mitochondria have also active roles in a diversity of other processes, including inflammation, whereas their functions seem to influence some of cancer hallmarks, which include evasion of cell death, genome instability, tumor-promoting inflammation and metastasis. Defects in mitochondrial function which are associated with bioenergetic deficiencies can lead to nDNA genome instability, resistance to apoptosis and induction of NADPH oxidase which is implicated in ROS production. Researches have demonstrated that mtDNA shows a high mutations rate most of which are responsible for mild mitochondrial dysfunction and its essential role in tumorigenesis, whereas enhanced mitochondrial biogenesis is frequently recorded in cancer cells. Although mtDNA has been implicated in cancer pathogenesis, its role remains to be defined. The aim of the current article was to examine the role of mtDNA mutations in cancer pathogenesis.

Keywords: Mitochondria, mt DNA, Mutations, Cancer, Polymorphism 


\section{Introduction}

Mitochondria are semi-autonomous subcellular, membrane-enclosed, organelles that are essential for energy production, providing substrates for intracellular metabolic pathways (Elmore, 2007), whereas have a unique biology whose genomic replication is independent of the cell cycle and accomplished with a distinct enzymatic complex (Wai et al., 2008). They are responsible for production of adenosine triphosphate (ATP) through the process of oxidative phosphorylation (OXPHOS), calcium storage for cell signaling pathways, production of reactive oxygen species (ROS), redox molecules and metabolites, regulation of cell signaling, mediating cell growth and cell death processes, and biosynthetic metabolism. Mitochondria have a central role in maintaining cellular homeostasis by regulating energy metabolism, cell survival and proliferation, whereas have also implicated as central regulators of other processes or influence cellular signaling and survival pathways, including inflammation, immunity and migration (Elmore, 2007). Those organelles are able to migrate within the cell, fuse and divide through rapid fusion and fission processes and undergo turnover through mitophagy, a specialized form of autophagy (Wai et al., 2008).

The human mitochondria have their own genome that is organized into DNA-protein complexes known as mitochondrial nucleoids, which are relatively stable genetic ingredients. Human cells contain approximately 2,000 mitochondria per cell and an average of between 1.4 and 7.5 mtDNA molecules per nucleoid (Wallace and Chalkia, 2013). The mtDNA is a negatively supercoiled circular double stranded DNA molecule, consists of 16,569 bp. One strand is known as light(L) and the other one as heavy $(\mathrm{H})$, according to sedimentation properties. Sequence analysis of human mtDNA showed that more than 93\% of mtDNA sequence considered coding and contains 37 genes, 28 of which are encoded in the $\mathrm{H}$ strand and 9 in the L strand (Wallace and Chalkia, 2013). It encodes 13 genes of the electron transfer chain (ETC), which are responsible for production of cellular ATP through the process of OXPHOS (Anderson et al., 1981). More specifically, 7 genes of nearly 45 polypeptides of the ETC complex I (ND13, ND4L and ND4-6), 1 gene of the 11 polypeptides of complex III (Cytb), 3 genes of the 13 polypeptides of complex IV(COI-III), and 2 genes of the 15 polypeptides of complex V (ATP6 and ATP8) (Wallace and Chalkia, 2013). mtDNA also encodes 2 ribosomal RNAs (rRNA), 18S and 16S, 22 tRNAs and also contains one non-coding region, the D-loop (Wallace and Chalkia, 2013; Wallace, 1994). All of these proteins are subunits of an OXPHOS system localized at the mitochondrial inner membrane (Stewart and Chinnery, 2015).

There are also 2 hypervariable regions (HV) localized in the control region of mtDNA, HV I (nucleotides 16024-16383) and HV II (57-372) (Liu et al., 2001; Czarnecka et al., 2006). The 
hypervariable region mutates several hundred times more frequently than other mtDNA regions. It is a place where multiple short tandem repeats (STR) are observed, and the majority of them are CA (cytosine, adenine) repeats and short base-repetitive sequences (microsatellite instability, MSI). MSI is diffused in the whole human genome (Stewart and Chinnery, 2015). mtDNA encodes a large number of proteins needed for its molecular architecture and biological functions, known as nuclear-encoded mitochondrial proteins (NEMtPs), and more than1,500 are required for mitochondrial biogenesis, assembly of the respiratory chain and the maintenance of mtDNA, transcription and translation processes, as well as to carry out biochemical functions, and catabolytic pathways (Egea et al., 2005; Neupert and Herrmann, 2007), that are strictly essential for life.

Cancer is a complex genetic disease, comprising over 200 types and caused by a variety of factors, including mutations in proto-oncogenes and tumor suppressor genes. Cancer development is a multistep process, involving genome instability, which leads to sustained proliferative signaling, the evasion of growth suppressors, resistance to cell death, tumor angiogenesis, invasion and metastasis (Hanahan and Weinberg, 2011). Other hallmarks of the cancer cell are the capacity to evade the immune system and to generate reprogramming of the energy metabolism system (Warburg, 1956).

Cancer cells deregulate their cell cycle, impair apoptosis, promote a higher proliferation rate due to their ability to reprogramme metabolism (Hanahan and Weinberg, 2011). This is achieved by increasing aerobic glycolysis, the well-known Warburg effect, which supplies the metabolic intermediates used in anabolic processes (Vander Heiden et al., 2009; Ward and Thompson, 2012), and is a tumor cell metabolic abnormality. Otto Warburg observed that cancer cells prefer aerobic glycolysis to OXPHOS, however, these cells do not uptake oxygen like normal tissue cells, even under a normal oxygen environment (Warburg, 1956; Wu and Zhao, 2013). Consequently, there is sufficient evidence to support the hypothesis that tumor-related metabolic abnormalities involve defects in mitochondrial function, since many of the metabolic genes whose mutations can cause cancers are mitochondrial genes or nuclear encoded genes that are relevant to mitochondrial biogenesis and function. In addition, OXPHOS is downregulated in most cancer cells, the combination of high glycolysis and low OXPHOS becoming a feature used to diagnose early stages of cancer and as a marker of tumor progression (Formentini, 2010). Other mitochondrial functions have been involved in cancer initiation and progression (Senf and Ronai, 2016), as through various mechanisms cellular functions interact with genetic alterations in the mitochondria to provide a mechanism contributing to cancer appearance and progression (Giompazolias and Tait, 2016; Rogalinska, 2016). Moreover, cancer cells show increased levels of energy requirements and proliferation and it is possible that mitochondria may play a crucial role in cancer induction and progression (Rogalinska, 2016; Vyas, 2016; Stefano and Kream, 2015). 
The role of the nuclear genome (nDNA) in the development of neoplasms, has been examined and the current review has been focused on the mitochondria, particularly on mtDNA and its role in the neoplastic process (Czarnecka and Bartnik, 2009). mtDNA seems to be essential for driving tumorigenesis and complete mtDNA reduction prevents the initiation of tumorigenesis. Furthermore, mtDNA copy number and variants are modulated at different stages of tumorigenesis. Altering a tumor cell's mtDNA substance leads to changes to nuclear gene expression that directly affect the severity of the tumor phenotype (Lee et al., 2016).

Somatic mtDNA mutations have been found in almost all cancers examined to date, and strengthen Warburg's hypothesis (Warburg, 1930) that mitochondrial abnormalities are involved in development of cancers. Many mitochondrial abnormalities in cancers, at the mtDNA level, both at genetic and metabolic levels, have been reported (Modica-Napolitano and Singh, 2002; ModicaNapolitano and Singh, 2004). mtDNA somatic mutations are associated with cancer and aging and are present inside the tumor but not in the normal tissue, occur in various types of cancer cells including breast, ovarian, prostate, bladder, lung, and colon (Czarnecka et al., 2006; Czarnecka et al., 2010). In addition, such mutations were identified in pre-malignant conditions (Sui et al., 2006) and most of them were detected in the control region of mtDNA that encompasses 1,000 nucleotides (nt) of mtDNA genome (Sui et al., 2006; Mancuso et al., 2007).

The mitochondrial genomes of human tumors frequently carry clonally expanded mtDNA mutations (He et al., 2010; Coller et al., 2001), and a subset of those mutations directly contributes to cancer progression by accelerating primary tumor growth (Arnold et al., 2009) and according metastatic potential (Ishikawa et al., 2008) to tumor cells. However, it remains unknown whether the nuclear point mutation instability of human cancers (Bielas and Loeb, 2005) is summarized in the mitochondrial genome.

Mitochondrial genome mutations can be present also in germline cells. The germline mtDNA mutation might contribute to mitochondrial disease and certain cancer etiology in the descendant. In the germline cells, two mtDNA polymorphisms, in the NADH dehydrogenase 3 (ND3) gene at position $10398 \mathrm{G} \rightarrow \mathrm{A}$ and in the cytochrome c-oxidase (COI) gene, have been associated with cancer risk. The polymorphism of the ND3 gene was associated with an increased risk of invasive breast cancer in both pre- and postmenopausal females. Cytochrome oxidase subunit I (COI) gene mutations are a frequent polymorphism and have been linked to prostate cancer susceptibility (Mancuso et al., 2007; Liu et al., 2003; Brandon et al., 2006; Wallace, 2005). 
mtDNA shows a high susceptibility to mutation that is attributed to its exposure to deleterious ROS produced by OXPHOS, inefficient repair system and absence of protective nuclear histone proteins. Therefore, the accumulation of mutations in mtDNA is approximately 10-100 times higher than that observed in nDNA (Fernández-Silva et al., 2003). Most mutations in the regions of coding sequences lead to transformations in OXPHOS system subunits, and in rRNA or tRNA molecules, whereas mutations in the D-loop region may have an influence on replication and transcription of mtDNA (Coskun et al., 2004).

mtDNA mutation, deletion or depletion leads to the disruption of the ETC that is associated with an increasing number of diseases (Dimauro and Davidzon, 2005). Moreover, as already mentioned, mtDNA copy number and variants have been associated with cancer (Kirches et al., 2001; Liang and Hays, 1996). However, it remains to be defined whether the mtDNA copy number regulation and the ability of mtDNA to acquire de novo variants can lead to tumorigenesis.

Alterations in mitochondrial functions have been strictly associated with cancer (Wallace, 2012), as several studies have shown that mutations in mitochondrial proteins encoded by either the mitochondrial or the nuclear genome may promote cancer development and progression (Vyas et al., 2016; Guaragnella et al., 2014; Guerra et al., 2017; Gaude and Frezza, 2014).The mitochondrial involvement in the process of carcinogenesis has been confirmed as was found a nDNA mutation of fumarate hydratase in myoma and nephroma (Lehtonen et al., 2004). Another study showed nDNA mutations in 3 out of 4 subunits of succinate dehydrogenase belonging to complex II of the respiratory chain system (Bayley et al., 2006) in paraganglioma and pheochromacytoma. mtDNA is probably also involved in colorectal cancer patients due to its elevated levels in peripheral blood leukocytes $(\mathrm{Qu}$, et al., 2011).

\section{Somatic and Germline mtDNA Mutations and Cancer}

Nuclear (n)DNA-encoded mitochondrial gene mutations have been identified in cancer cases (Lehtonen et al., 2004; Astuti et al., 2001; Vanharanta et al., 2004), finding that led to the hypothesis that mtDNA mutations might also be involved in cancer etiology. Mutations in nuclear-encoded components of the mitochondrial translation mechanism accumulate non-repaired nDNA and mtDNA that may promote cellular transformation and tumor appearance. Moreover, mutations in nuclear genes responsible for mtDNA biosynthesis and integrity maintenance, such as POLG, mtTFA, PGC-1, NRF-1, NRF-2, isocitrate dehydro-genase (IDH), SDH family members(SDHA, SDHB, SDHC, SDHD), fumarate hydratase (FH), SIRT1-3, POLG, TWINKLE and OPA1 are frequently involved in carcinogenic processes (Yu et al., 2016; Parker and Metallo, 2015; Reitman et al., 2011). 
Nuclear-encoded polymerase gamma (POLG) is the only DNA polymerase that functions in human mitochondria, and due to its ability to avoid lesions by translation synthesis, is vital for maintaining the genetic integrity of mtDNA. POLG mutations are able to promote mtDNA mutations, the accumulation of unrepaired lesions or can even prevent DNA replication in cancer (Stewart and Chinnery, 2015; Warburg, 1956; Wu and Zhao, 2013; Wallace and Chalkia, 2013; Akhmedov and MarínGarcía, 2015; Yakes and Van Houten, 1997). IDH1 and IDH2, mitochondrial and TCA cycle-related proteins, are frequently mutated in tumors, such as glioblastoma. Research in glioblastoma and acute myeloid leukemia have identified recurrent missense mutations that affect specific residues of the nuclear genes IDH1 and IDH2 (Parker and Metallo, 2015).

The contribution of mtDNA mutations to tumorigenesis cannot be assessed as is mainly associated with the genetics of the organellar genome. Most importantly, the vicinity of ROS produced during normal metabolic reactions increases risk of mtDNA disturbance and instability (Giampazolias and Tait, 2016). The effect of ROS on alterations to mtDNA is supported by a general increase in some cancers of transitions at purines (Polyak et al., 1998). ROS production, may be the cause of increased tumorigenicity, since ROS affect transcription factors, signal transduction kinases, regulatory phosphatases and angiogenic factors (Larman et al., 2012). This risk to DNA damage, in combination with fewer repair mechanisms relative to the nuclear genome, results in an mtDNA mutation rate higher than the nuclear genome (Khrapko et al., 1997). Empirical evidence suggests that endogenous mutational processes influence the mtDNA mutation rate more than the known exogenous carcinogens factors such as environmental chemical and ultraviolet light (Ju et al., 2014). mtDNA mutations have been recognized in the non-coding and coding regions of the mtDNA (Chinnery et al., 2002; Copeland et al., 2002). After analyzing the whole-genome data generated by "The Cancer Genome Atlas Research Network (CGARN)", it was found that the majority of coding mutations concerned the subunits of the electron transport chain complex (NADH dehydrogenase, cytochrome b and cytochrome c oxidase) (Larman et al., 2012).

mtDNA cancer mutations and alterations could either arise in the female germline and predispose to cancer development, known as oncogenic germline mutations or arise in the mtDNAs of the tissues and participate in the tumor progression process, known as tumor-specific somatic mutations (Guerra et al., 2017). Another report of the mtDNAs of bladder, head and neck, and lung cancers showed that 51\% contained tumor-specific mtDNA mutations (Fliss et al., 2000). Similar researches of mtDNA control region variation recorded that $48 \%$ of gastric tumors harbored tumor-specific mtDNA mutations (Wu et al., 2005), 39\% of hepatocellular carcinomas harbored mtDNA control region mutations (Lee et al., 2004) and 68\% of hepatocellular carcinomas had control region mutations (Nomoto et al., 2002). 
mtDNA control region mutations were mainly revealed in glioblastomas but also two coding region mtDNA variants (Kirches et al., 2001), whereas neurofibromas from neurofibromatosis patients harbored only control region mutations (Kurtz et al., 2004).

The first direct causal relation between a mtDNA mutation and cancer was based on the identification of the T8993G(L156R) germline mutation in the ATP6 gene as heteroplasmic in prostate cancer patient and also proved its tumorigenic ability in a nude mouse prostate cancer model (Petros et al., 2005). Moreover, germline mtDNA COI gene mutations can cause prostate cancer and mutant mtDNA genes can be oncogenes (Petros et al., 2005). It has also been shown that heterozygous germline mutations in SDHB, SDHC, SDHD and SDHAF2 are responsible for hereditary paragangliomas and pheochromocytomas (Burnichon et al., 2010). Germline and somatic mutations in mtDNA take place mainly in two parts of the hypervariable (HV) sites in the non-coding human mtDNA control region, HV1 and HV2 (Stoneking, 2000).

The first evidence that a mtDNA mutation in cancer cells could be functionally significant based on a study of a renal adenocarcinoma in which 50\% of the mtDNAs contained a $294 \mathrm{nt}$ in-frame deletion in the mtDNA ND1 gene resulting in a reduced mRNA (Horton, 1996). In another research was recorded that the frequency of somatic mtDNA mutations ranged from $13 \%$ in glioblastoma to $63 \%$ in rectal adenocarcinomas (Larman et al., 2012).

mtDNA variants commonly found as germline polymorphisms (or germline mutations) or somatic mutations (cancer cells) comprise point mutations, mono- or dinucleotide repeats, insertions, deletions and mtDNA copy number variations (Brandon et al., 2006; Petros et al., 2005; Kirches, 2009). mtDNA variation of thyroid tumors were also analyzed and showed that $49 \%$ of tumors had control region somatic mutations, 52\% of tumors harbored coding region somatic mutations (Maximo et al., 2002) and $23 \%$ of 13 papillary thyroid carcinomas had coding region mtDNA mutants (Jen Yeh et al., 2000).

Some somatic mtDNA mutations seem to promote tumorigenesis and others to promote cancer metastasis due to an increase in ROS production (Ishikawa et al., 2008; Petros et al., 2005). mtDNA mutations influence genes that encode proteins of the respiratory chain complexes resulting in a deficient flow of electrons and protons through that membrane, which consequently increases its potential in neoplastic cells (Modica-Napolitano et al., 2007). Nevertheless, a definitive association between mtDNA depletion/somatic mutations and tumorigenesis or cancer progression is still remains unclear. 
Prior to cell division a normal cell can comprise both mutated and normal wild-type mtDNA, a condition known as heteroplasmy, and it is known that most alterations within the mtDNA of a neoplastic cell are of homoplasmic nature. One type of mtDNA initiates to dominate in the mitochondrion, process known as functional advantage, as a result of an intramitochondrial selection. Another selection at the cellular level concerns one type of the mitochondria, that contains one type of mtDNA, and initiates to dominate (Augenlicht and Heerdt, 2001). During a division, the cell attempts to change the rate between the mutated and normal mtDNA and to acquire homoplasmy, namely, a domination or absolute presence of only one type of mtDNA, procedure known as replicative segregation. More specifically, during the process of cell division, a replicative segregation occurs with a selective advantage of the altered mitochondria. The period required for a replicative segregation to happen corresponds with the phase of a neoplastic transformation (Augenlicht and Heerdt, 2001). The cell that contains mutated mtDNA is growth-privileged and starts to proliferate, generating descendants that now contain only one type of mtDNA, procedure that initiates tumor growth. The mentioned findings are the classical model of a cell attempting to accomplish homoplasmy. It has been suggested, based on a mathematical model, that homoplasmy is acquired through a random segregation of the mitochondria during the cell division process (Arnold et al., 2009). The subsequent generations of descendant cells either maintain heteroplasmy or, through a genetic trend, reach at homoplasmy. The genetic trend can either results in deletion of rare variants of mtDNA or it can be installed, processes that can occur in neoplasia (Coller et al., 2001).

Other researches showed that the majority of the mtDNA mutations seemed to have homoplasmic nature, that means same sequence in all mtDNA molecules. However, heteroplasmy, that means the presence of more than one mtDNA sequence in a cell, could contribute to heterogeneous mitochondrial morphologies and is associated with metabolic flexibility and cancer metastasis (Stefano and Kream, 2016). Based on the cell level, mutations may be homoplasmic, more than 95 to 100\%, high heteroplasmic, more than 20 to less than 95\%, low heteroplasmic more than 0.5 to less than $20 \%$ or rare, $0.5 \%$ or less (Ahn et al., 2015).

The selective development of cells with a mutated mtDNA may be a result of alterations that happened simultaneously in nDNA, which stimulates these cells to proliferate and creates a homogenic population in the previously modified mitochondria. The rate of normal and mutated mtDNA is responsible for the appearance and degree of symptom severity in mitochondrial diseases. The domination of a mutated mtDNA in a cell results in disturbances of energy production in the process of OXPHOS, which leads to cell and tissue damage (Reid, 1983). The clinical demonstration of those disturbances depends on the type of mtDNA damage, the degree of heteroplasmy and the sensitivity of a 
specific tissue to cell respiration problems. The domination of the mutated mtDNA triggers symptoms gradually. The other mechanism of carcinogenesis that concerns mtDNA involves the introduction of mtDNA fragments into the cellular nucleus (Reid, 1983; Shay and Werbin, 1992).

\section{Homoplasmic and Heteroplasmic Mutations}

Somatic cells comprise hundreds to several thousand mitochondria, and each of them contain 110 copies of mtDNA genes. mtDNA often incurs spontaneous mutations, due to its structure, and many of those are considered to be polymorphisms. Among the large number of mtDNA haplotypes, one type begins to dominate which is characteristic of a neoplastic cell and which is usually discovered as homoplasmy in tissue lesions or aging. mtDNA seems to be unique and the existence and level of heteroplasmy may depend on the tissue type. Point mutations in neoplasms are usually homoplasmic whereas heteroplasmy, often is present in tumors or normal aging cells, and involves deletions. However, it is not clear whether homoplasmic mutations occurring in mtDNA appear de novo or whether they exist from the beginning (Huanzheng et al., 2019). In a study conducted by Polyak et al. (Polyak et al., 1998), the formation of homoplasmic mtDNA was observed, and was found a selective dominance of one type of mtDNA and to homoplasmy. It is possible that the mutated mtDNA is replicated to a serious extent than the wild-type DNA. During cancer pathogenesis the process continues long enough for neoplastic cells to allow the 'wild-type mtDNA' to be replaced by the mutated one.

A recent hypothesis supports that homoplasmy or heteroplasmy in the neoplastic cells takes place when the descendant cells acquire a group of mitochondria of the same haplotype during cell division. Through a repeated division of the mitochondria that contain two types of the mitochondrial haplotype, the wild-type and the mutated one, mitochondria of the same haplotype are formed inside of the cytoplasmic domains (Bianchi et al., 2001). Heteroplasmy is not detectable as there is predominance of wild-type mitochondria in a normal cell. During cell division, a separation of the mitochondrial genome probably occurs in a cell. Each of the two descendant cells receives the mitochondria including only one type of mtDNA. The final result is that one descendant cell contains the wild-type mtDNA, whereas the other one has the mutated type. The cell that contains the mutated mtDNA begins the procedure of transformation and spreading. Heteroplasmy or homoplasmy, consequently, appears at an early stage of cancer development, and during the neoplasm spreading new variants of heteroplasmy are able to be formed in a cell (Bianchi et al., 2001). In epithelial tissue neoplasms, at least one homoplasmic mtDNA mutation is present (Okochi et al., 2002; Kumimoto et al., 2004).

More cell divisions associated with the transformation of the cell into a neoplastic one are supposed to both enable further mutations and promote spreading. This is the reason for an increased 
number of mtDNA mutations in tumors compared with the normal tissue (Coller et al., 2001), and for the fact that in the majority of neoplastic tumors, alterations in mtDNA are characterized by an homoplasmic nature. Moreover, because of the great number of mutations occurring in neoplasms, mtDNA, such as nDNA, can become a neoplastic marker. Several techniques of detecting mutations in the urine (Fliss et al., 2000), blood (Okochi et al., 2002) or saliva (Fliss et al., 2000) of cancer patients have been proposed. In head and neck neoplasms $67 \%$ of alterations detected in the tumor associated with alterations in the patients' saliva (Fliss et al., 2000).

Zhu, et al. (Zhu et al., 2005) compared the detectability of mtDNA mutations in specimens acquired from a fine-needle aspiration biopsy and in postoperative tissue from breast cancer, and in the postoperative samples they found at least one mutation. The biopsy specimens contained mtDNA mutations in $78,9 \%$ of the cases. In $21,1 \%$ of the patients showed no mutations, which means that each of the alterations present in the bioptic material was also present in the postoperative tumor sample.

\section{mtDNA Silent Mutations}

It is considered that the mitochondrial replication is a controlled procedure and a signal that comes from the functionally modified mitochondria causes an exaggerated replication to improve the cell functionality (Attardi et al., 1995). This observation suggests that each of the mtDNA mutations influences their functionality. Moreover, silent mutations, which do not cause changes in the protein, affect the functionality of the mitochondria. Two hypotheses have been suggested for the mentioned effect of the silent mutations. The first supposes that these silent mutations transfer with them some, extremely difficult to be detected, unidentified mutations, that lead to a selective domination of the mutated genome and a replacement of the wild-type by the mutated genome.

It is possible that when the mitochondrial genome does not incur recombination, a mutation is to some degree installed, resulting in genetic disorder, and causes heteroplasmy followed by homoplasmy in the following generations (Bianchi et al., 2001; Hofhaus and Gattermann, 1999). The second theory supports that the mitochondrion itself controls its own replication. In case its functioning begins to change, such a 'mutated' mitochondrion starts to replicate extensively, and it begins to dominate in the cell (Hofhaus and Gattermann, 1999). It is also unknown how these silent mtDNA mutations affect and regulate the very process of translation, especially when this procedure in mtDNA differs slightly from the cytoplasmic one (mtDNA mRNAs do not have 5' and 3' UTRs) (Brandon et al., 2006).

It seems that apart from mtDNA mutations the essential factor is an additional existence of polymorphisms, that can cause an undetectable, increase of ROS generation. It is possible that 
polymorphisms might be those additional changes that escort the silent mutations which might promote the selective domination of the mutated mtDNA (Bianchi et al., 2001).

mtDNA Alterations in Cancer Initiation and Progression

Mitochondrial's genetics leads to evolutionary interactions driving appearance and proliferation of mutations, whereas the interactions with nuclear genes result in an extra complexity level regarding the role of mtDNA in cancer pathogenesis. The mitochondrial proteome contains thousand proteins, however a small rate are encoded by mtDNA (Pagliarini et al., 2008). The remained are encoded by genes located in the nuclear genome and are responsible for mitochondrial replication and expression. Mutations to such genes may have direct effects to mtDNA instability and copy number, and nuclearencoded genes may affect mitochondrial function in ways that also affect cancer development and progression (Giompazolias and Tait, 2016). A restricted number of nuclear-encoded genes have been supposed to alter the mitochondrial genome itself. It has been revealed that a nuclear-encoded mitochondrial transcription factor A (TFAM) cut-back occurring from frameshift mutations in a coding mono-nucleotide repeat of the gene in colo-rectal cancer cell lines led to mitochondrial instability and reduced mitochondrial copy number (Guo et al., 2011). On the other hand, somatic mutations in nuclear-encoded POLG, did not seem to increase mtDNA mutations, although they led to mitochondrial dysfunction through a decrease in mtDNA content (Linkowska, 2015). Except for immediate affect of mtDNA, genes from outside the mitochondria can have serious effects on mitochondrial function. To be more specific, nuclear-encoded genes, that contribute to mitochondrial functions such as OXPHOS, can have mutations which increase the risk of cancer, produce oncogenic metabolites, or even initiate tumorigenesis (Zong et al., 2016; van Gisbergen et al., 2015).

Mitochondrial dysfunction leads to a higher frequency of spontaneous mutation in nDNA compared to the wild-type, dependent or independent of ROS, processes that may lead to cancer initiation and progression (Rasmussen et al., 2003).

Investigation of the roles of specific mtDNA mutation on cancer progression, requires the use of cybrid cells, that contain nuclear DNA from cancer cells with specific mtDNA mutation. Cybrid cells with specific mutant mtDNA in ND6 region in an in vivo mouse model system induces metastatic phenotype, indicating that specific mutations ND6 in complex I offer a survival advantage and induce metastasis (Ishikawa et al., 2008). Moreover, previous investigations showed increased growth of tumor size of cybrids with mutant mtDNA in vivo (Petros et al., 2005; Shidara et al., 2005).

However, a contradictory study, regarding cancer initiation, using xenographic tumor formation 
model showed that cybrids that transfer nDNA from tumor cells and mtDNA from normal cells resulted in tumor development, whereas those that transfer nDNA from normal cells and mtDNA from tumor cells did not lead to tumor development (Akimoto et al., 2005). The mentioned observations suggest that nDNA, but not mtDNA, is responsible for cancer initiation at least in a short term. mtDNA mutations deregulate mitochondrial respiratory enzyme complexes and it is considered that increase risk of cancer development. It has been demonstrated that defects in mitochondrial respiratory chain activity result in superoxide producing NADPH oxidase (Desouki et al., 2005) overexpression, increased damage and hypermutagenesis in the nDNA (Rasmussen et al., 2003; Singh et al., 2005; Singh, 2004; Delsite et al., 2003) and resistance to programmed cell death-apoptosis (Park et al., 2004). Those alterations in cellular phenotype contribute to the cancer development.

Metabolic dysregulation and its consequences induce a strong selective pressure on tumor cells. Therefore, acquiring somatic mtDNA mutations that affect OXPHOS appear to be an alternate mechanism for increasing tumor growth (Larman et al., 2012). These observation propose that at least one of those mtDNA mutations could provide a selective advantage to the cancer cell, supporting the hypothesis that mtDNA somatic mutations are seriously involved in promoting the proliferation of several types of tumor cells (Polyak et al., 1998).

The role of mtDNA damage on cancer progression, is demonstrated by the use of mitochondrial genomic knock-out $(\rho 0)$ with deficient in respiration. In a previous study was showed that tumor necrosis factor (TNF) and serum deprivation could not induce TNF-induced apoptosis in $\rho 0$ cells, whereas they induced apoptosis in parental cells and cells reconstituted by normal mtDNA (Higuchi et al., 1997). It was also showed that AKT activation is responsible for the inhibition of apoptosis in $\rho 0$ cells (Suzuki et al., 2008). Those findings suggest that mtDNA alteration is associated with apoptosisresistance phenotype of cancer. Moreover, reduction of mtDNA substance removed androgendependent prostate cancer cells to an androgen-independent phenotype in vivo and in vitro (Higuchi et al., 2006), induced epithelial to mesenchymal transition (EMT) alterations (Naito et al., 2008) and silencing of supposed tumor suppressor genes by hyper methylation of CpG islands (Xie et al., 2007).

TP53 is a nuclear-encoded tumor suppressor gene which acts through cell cycle regulation and other cellular mechanisms to regulate mitochondrial metabolism. Several missense TP53 mutations lead to proteins, which continue to successfully promote survival of normal or cancer cell (Kamp et al., 2016). It has been found that additional genes involved in the following mitochondrial functions, biogenesis, mitophagy, fission/fusion, cell death, oxidative stress, metabolism, and signaling (Vyas et al., 2016). 
Ras signaling pathway is one of the most important to induce cancer initiation and progression (Downward, 2003). Intracellular oxygen concentration regulated by mtDNA is responsible for cancer progression. Loss of mtDNA substance conversely induced activation of Ras oncogene responsible for the activation of AKT and ERK resulting in cancer progression (Cook et al., 2012). Ras activation was mediated by high farnesylation induced by the overexpression of 3-hydroxy-3-methyl-glutaryl-CoA reductase (HMGR), the eliminating enzyme of the mevalonate signaling pathway.

Hypoxia induces proteasomal degradation of HMGR. Well-differentiated cancer cells showed high mtDNA substance, consumed a large amount of oxygen and induced intracellular hypoxia. Loss of mt DNA decreased oxygen consumption and increased the oxygen concentration in the cells (Nguyen et al., 2007; Song et al., 2005). The hypoxic-to-normoxic alteration resulted in the overexpression of HMGR through inhibiting proteasomal degradation. Consequently, damage to mtDNA induced overexpression of HMGR through hypoxic to normoxic alteration. Eventually, the endogenous induction of the mevalonate signaling pathway activated Ras that mediates advanced phenonotype (Higuchi et al., 1997). The outcomes clarify a rational mechanism that directly connects the mitochondrial genome with the advanced progression of the disease. It is obvious that several mechanisms are produced by mtDNA damage(s) and may interact with each other to induce cancer progression.

Human 8-Oxoguanine glycosylase also known as hOGG1 is a DNA glycosylase enzyme that, in humans, is encoded by the OGG1 gene that acts as a repair enzyme of mtDNA. Zang et al. showed that hOGG1 overexpression in mitochondria results in an increased frequency of mutation in mt DNA (Zhang et al., 2007) and that generated hOGG1 transgenic mouse model showed obesity and increased frequencies of malignant lymphoma (Zhang et al., 2011), demonstrating that mtDNA damages can induce cancer initiation.

Several signaling pathways associated with cancer progression such as NF-кB (Biswas et al., 2003; Higuchi et al., 2002), AKT (Suzuki et al., 2008; Higuchi et al., 2006; Naito et al., 2008; Xie et al., 2007; Biswas et al., 2003; Higuchi et al., 2002; Guha et al., 2010a; Pelicano et al., 2006), AP-1 (Nishimura et al., 2001), ERK (Naito et al., 2008), JNK (Naito et al., 2008), and Calcineurin (Guha et al., 2010b) can be induced in $\rho 0$ cells.

\section{Mitochondrial Polymorphism and Cancer Risk}

Cancer research has focused on genetic variants in a large part of the control region that is known as the D-loop, which is a subset of the non-coding region found in many animal mtDNAs, and is created by accession of a third linear strand of DNA. Based on the association between the control region and 
mitochondrial replication and transcription, mutations in that loop may influence the copy number and regulation of mitochondria (Nicholls and Minczuk, 2014). In cancer research, D-loop mutations are the most well-studied of all mtDNA cancer variants (Masuda et al., 2012). D-loop mutations are also present in later phases of cancer (Lee et al., 2005), and higher rates of somatic D-loop mutations have been associated with poor prognosis in breast cancer (Kuo et al., 2010).

Those mutations may have possible implications for mitochondrial function in cancer, however it is unclear whether these variants are a causal or an associated finding (Masuda et al., 2012; Kuo et al., 2010; Akouchekian et al., 2009). Mitochondria protein-coding genes belong to four different complexes of the mitochondrial respiratory chain. Complex I (NADH dehydrogenase) is represented by seven mtDNA genes (ND1-6, including ND4L), a complex most frequently contains variants associated with tumorigenesis (Kurelac et al., 2013). ND5 is associated with somatic mutations (Larman et al., 2012; McMahon and La Framboise, 2014), which may change tumor progression (Iommarini et al., 2014). CYTB is the only gene, of Complex III, encoded by mtDNA, contains fewer somatic variants (Dasgupta et al., 2008; Dasgupta et al., 2009).

Germline mtDNA variants are useful for delegating individuals to certain haplogroups (Weissen steiner et al., 2016), which can then be associated with hereditary matrilineal relationships (van Oven, 2015). Although haplogrouping is mainly used for identifying relationships among individuals and populations, some haplogroups have sequence variants that also contribute to cancer susceptibility (Czarnecka and Bartnik, 2011; Lam et al., 2012; Blein et al., 2015). Moreover, some somatic mutations may represent haplogroup alteration (Salgado et al., 2008), confusing interpretability of mtDNA data. Somatic mtDNA alternations in cancer types are contain more nonsynonymous variants compared to synonymous ones (Larman et al., 2012; Kloss-Brandstatter et al., 2015).

The molecular mechanisms that are responsible for the association between mtDNA haplogroups and cancer development remains unclear and previous reports have shown controversial results (Booker et al., 2006; Fang et al., 2010; Hu et al., 2014; Li et al., 2015; Poynter et al., 2016; Singh and Kulawiec, 2009; Cano et al., 2014). Nevertheless, specific mtDNA haplogroups have been associated with the risk of prostate, colorectal, nasopharyngeal, gastric cancer, myelodysplastic syndromes, acute lymphoblastic leukemia, etc. (Yu et al., 2016; Booker et al., 2006; Fang et al., 2010; Hu et al., 2014; Li et al., 2015; Poynter et al., 2016; Singh and Kulawiec, 2009).

An over-representation of haplogroup I in cancer patients has been reported (Czarnecka et al., 2010), haplogroup $U$ has been associated with an increased risk of developing renal and prostate cancers (Booker et al., 2006), and haplogroup JT has been found to be associated with myelodysplastic 
syndromes susceptibility (Poynter et al., 2016). Moreover, haplogroups H, N and L have been found to be associated with the risk of developing pancreatic cancer, whereas haplogroup $\mathrm{K}$ has been identified as protective for this type of cancer (Verma et al., 2007). Haplogroups D4a and D5a have been found to be associated with an increased risk of esophageal cancer, whereas the $\mathrm{N}$ and $\mathrm{M}$ haplogroups have been reported as biomarkers for the favorable and poor survival in gastric cancer patients, respectively (Hu et al., 2014; Jiang et al., 2015). Another study (van Gisbergen et al., 2015), reported an association between the haplogroup M7b2, previously associated with leukemia and an increased risk of developing hematologic cancers.

Similar studies have described the risk of cancers associated with various mtDNA haplogroups in humans. Verma, et al. (Verma et al., 2007) analyzed a population of 1,503 autopsied cases, in which the haplogroups, were categorized into 30 haplotypes, i.e., F, B5, B4a, B4b, B4c, A, N9a, N9b, Y, M10+ M11+M12, M7a, M7b2, M7c, M8+Z+C, G1, G2, M9, D5, D4a, D4b, D4d, D4e, D4g, D4h, D4j, D4k, D4k, D4l, $\mathrm{D} 4 \mathrm{~m}$, and D4n. Multivariate logistic regression analysis showed that individuals with the haplogroup M7b2 tended to have an increased risk for hemopoietic cancer $(\mathrm{P}=0.037)$, having an odds ratio of 2.46 (95\% CI=1.06-5.73), whereas the results also indicated that haplogroup M7b2 was a risk factor for leukemia. In another study by Booker, et al. (Booker et al., 2006) 9 main European haplotypes (H, I, J, K, $\mathrm{T}, \mathrm{U}, \mathrm{V}, \mathrm{W}$, and $\mathrm{X}$ ) were analyzed in a series of patients with renal and prostate cancers. The authors used the A12308G substitution in tRNALeu2 as a mtDNA haplogroup $U$ marker, and found that patients transferring this haplogroup showed an increased risk of renal $(\mathrm{OR}=2.52)$ and prostate cancer $(\mathrm{OR}=$ 1.95). Another study in African-American females showed that the G10398A substitution in ND3 was associated with an increased risk (OR = 1.6) of breast cancer (Canter et al., 2005), whereas they also reported one of the first cases of synergy among single-nucleotide polymorphisms (SNP). The T4216C substitution alone in ND1 accorded no increased risk of cancer development. However, in case the T4216C substitution was present with G10398A, the risk of breast cancer was increased (OR =3.1). Nevertheless, some of the most robust association data have been reported for haplogroup T (M184) and the risk of colorectal cancer in European-American descendants (Li et al., 2015).

Darvishi, et al. (Darvishi et al., 2007) analyzed mtG10398A (Ala $\rightarrow$ Thr) polymorphism in a haplotype constituting mtDNA haplogroup $\mathrm{N}$ and its sub-lineages for its contribution to higher risk for breast cancer. The authors analyzed approximately 1,000 complete human mtDNA sequences worldwide, and they confirmed that mt10398A allele confers a risk of breast cancer. The study also observed that 10398A mtDNA polymorphism provides a higher risk for esophageal cancer. Moreover, an association between mtDNA haplogroup D4a and D5a and increased risk of esophageal cancer was reported in a recent study by Singh et al. (Singh and Kulawiec, 2009). After analyzing mtDNA 
polymorphism in European-American females Bai et al. (Bai et al., 2007) observed that A10398G (OR = 1.79) and $\mathrm{T} 16519 \mathrm{C}(\mathrm{OR}=1.98)$ increase breast cancer risk, whereas, in contrast, $\mathrm{T} 3197 \mathrm{C}(\mathrm{OR}=0.31)$ and G13708A (OR = 0.47) were found to decrease breast cancer risk. Wang, et al. (Wang et al., 2007) assessed polymorphisms in mtDNA associated with increased risk of pancreatic cancer, and found no significant associations with pancreatic cancer in Caucasian cases. It is probable that polymorphism in other mitochondrial genes or in connection with nuclear genes involved in OXPHOS may contribute to pancreatic cancer development. A limitation of some of the mentioned studies, is that the potential influence of population stratification was not taken in to account. A population stratification of these studies is essential to provide convincing evidence for the association of mtDNA polymorphism and risk for cancer.

The most common mtDNA polymorphisms that have been associated with an increased risk of cancer are T16189C (D-Loop) that has been associated with endometrial cancer, G10398A (A114T at ND3 gene) and the deletion $\Delta$ mtDNA4977(Liu et al., 2001; Liu et al., 2003; Canter et al., 2005; Darvishi et al., 2007; Yu et al., 2008; Zhang et al., 2003; Liou et al., 2010), that is the most common deletion in the mitochondria, and takes place between nucleotides 8,470 and 13,477 of the human mtDNA. It also contains 5 tRNA genes, 4 genes encoding subunits of NADH dehydrogenases, COIII and ATPase genes, producing a smaller mt DNA molecule that results in a decrease in ATP production and to abnormal ROS generation (Peng et al., 2006).

\section{Mitochondrial Copy Number and Cancer Risk}

Except for structural abnormalities in mtDNA, in cancer have been identified alterations in mtDNA copy number. A raised mtDNA content has been found in primary head and neck squamous cell carcinoma, papillary thyroid carcinoma and endometrial cancer, in contrast to gastric cancer, which exhibits mtDNA depletion (Wang et al., 2005; Su et al., 2016; Singh et al., 2015). It is possible that the mtDNA copy number in cancer depends upon the specific site of mutation associated with that cancer type. Consequently, an increase in mtDNA copy number may be compensate mitochondrial dysfunction or mutations in nuclear genes indirectly implicated in controlling mtDNA copy number. On the contrary, mutations in the D-loop region, which control mtDNA reproduction, would lead to a decreased copy number (Wei Guo et al., 2013).

In many cancer cases, mtDNA fewer copies are accompanied by a decrease in mitochondrial genes expression, suggesting a suppressed mitochondrial activity in these cancer cases. mtDNA damage may lead to mtDNA copy number changes, and in the obtainment of new point mutations and deletions in mtDNA, damaged mitochondrial function and alterations in cell and tissue viability. mtDNA repair 
mechanism dysfunctions which are responsible for mtDNA replication and repair, may increase the accumulation of mtDNA mutations, despite the fact that mitochondria have nDNA repair pathways, such as base excision repair, miss-match repair and recombinational repair (Akhmedov and Marín-García, 2015).

The mtDNA copy number is associated with the incidence of key driver mutations that cause normal cells to become malignant (Reznik et al., 2016; Egea et al., 2005). Although the mtDNA copy number can influence the level of transcription of mtDNA genes, not all cancer types exhibit a relation between the expression of respiratory genes and mtDNA copy number (Reznik et al., 2016).

The possible causative mechanism of decreased mitochondrial copy numbers may be associated with D-loop mutations, since this locus mediates mtDNA reproduction (Lee et al., 2005). A high copy number of mitochondria (and genomes contained therein) are present in a normal cell.

The results after comparisons of mtDNA in 15 cancer types with normal adjacent cells showed that 7 had decreased mtDNA copies in tumor cells (bladder, breast, esophageal, head/neck squamous cell, kidney, and liver), 1 increased mtDNA copy in tumor cells (lung adenocarcinoma), and 7 had no difference from normal mtDNA content (colorectal, kidney, pancreatic, prostate, stomach, thyroid, and uterine) (Reznik et al., 2016). However, those standards are not entirely consistent with studies of individual cancer, which may reflect tumor-specific standards (Salgado et al., 2008), as it has been found that thyroid (Savagner et al., 2001) and pancreatic (Lynch et al., 2011) cancer cells are generally enriched with mitochondria, which may be a consequence of cell compensation for deficient OXPHOSP and lower ATP production per mitochondrion and contribute to increased cancer risk. On the other hand, hepatocellular carcinoma cells are mitochondrially limited (Lee et al., 2004).

\section{Conclusion}

Mitochondria play a significant role in OXPHOSP and apoptosis. Alterations in mtDNA may disturb these processes and lead to the abnormal function of the cell. These abnormalities lead to mt DNA mutations and polymorphisms, and have been observed in many human cancers. Several mechanisms are generated by mtDNA damage(s) and may contribute to induce cancer initiation and progression. However, whether they are a consequence or a cause of cancer remains unclear.

Consequently it is obvious that further research is required to investigate the importance of mtDNA polymorphism and risk of cancer, to identify D-loop region polymorphisms that result in mtDNA copy number alterations, nuclear genes that are able to control mtDNA copy number, genetic and epigenetic alterations in the nucleus associated with mtDNA polymorphisms,functional alterations 
associated with mtDNA copy number, and the possible role of synergy between different polymorphisms in mtDNA and nDNA.

\section{References}

Ahn EH, Hirohata K, Kohrn BF, Fox EJ, Chang CC, Loeb LA. Detection of ultrarare mitochondrial mutations in breast stem cells by duplex sequencing. PLoS One 2015; 10: e0136216.

Akhmedov AT and Marín-García J. Mitochondrial DNA maintenance: An appraisal. Mol Cell Bio-chem 2015; 409: 283305.

Akimoto M, Niikura M, Ichikawa M, Yonekawa H, Nakada K, Honma Y, Hayashi Y-Iet. Nuclear DNA but not mtDNA controls tumor phenotypes in mouse cells. Biochem Biophys Res Commun 2005; 327: 1028-1035.

Anderson S, Bankier AT, Barrell BG, de Bruijn MHL,Coulson AR, Drouin J, Eperon IC, Nierlich DP, Roe BA, Sanger F, Schreier PH, Smith AJH, Staden R, Young IG. Sequence and organization of the human mitochondrial genome. Nature 1981; 290: 457-465.

Arnold RS, Sun CQ, Richards JC, Grigoriev G, Coleman IM, Nelson PS, Hsieh C-L, Lee JK, Xu Z, Rogatko A, Osunkoya AO, Zayzafoon M, Chung L, Petros JA. Mitochondrial DNA mutation stimulates prostate cancer growth in bone stromal environment. Prostate 2009; 69: 1-11.

Astuti D, Latif F, Dallol A, Dahia PL, Douglas F, George E, Sköldberg F,Husebye ES,Eng C, Maher ER. Gene mutations in the succinate dehydrogenase subunit SDHB cause susceptibility to familial pheochromocytoma and to familial paraganglioma. Am J Hum Genet 2001; 69: 49-54.

Attardi G, Yoneda M, Chomyn A. Complementation and segregation behavior of disease-causing mitochondrial DNA mutations in cellular model systems. Biochim Biophys Acta 1995; 1271: 241-248.

Augenlicht LH and Heerdt BG. Mitochondria: integrators in tumorigenesis? Nat Genet 2001; 28: 104-105.

Bai RK, Leal SM, Covarrubias D, Liu A, Wong LJ. Mitochondrial genetic background modifies breast cancer risk. Cancer Res 2007; 67: 4687-4694.

Bayley JP, van Minderhout I, Weiss MM, Jansen JC, Oomen PH, Menko FH, Pasini B, Ferrando B, Wong N, Alpert LC. Mutation analysis of SDHB and SDHC: novel Germline mutations in sporadic head and neck paraganglioma and familial paraganglioma and/or pheochromocytoma. BMC Med Genet 2006; 7: 1.

Bianchi NO, Bianchi MS, Richard SM. Mitochondrial genome instability in human cancers. Mutat Res 2001; 488: 9-23.

Bielas JH and Loeb LA. Mutator phenotype in cancer: timing and perspectives. Environ Mol Mutagen 2005; 45: $206-213$.

Biswas G, Anandatheerthavarada HK, Zaidi M, Avadhani NG. Mitochondria to nucleus stress signaling: a distinctive mechanism of NFkappaB/Rel activation through calcineurin-mediated inactivation of IkappaBbeta. J Cell Biol 2003; 161: 507519.

Blein S, Bardel C, Danjean V, McGuffog L, Healey S, Barrowdale D, Lee A ,Dennis J, Kuchenbaecker KB, Soucy P,Beth Terry M, Chung WK,Goldgar DE, Buys SS,Breast Cancer Family Registry: Janavicius R, et al. An original phylogenetic approach identified mitochondrial haplogroup T1a1 as inversely associated with breast cancer risk in BRCA2 mutation carriers. Breast Cancer Res 2015, 17: 61.

Booker LM, Habermacher GM, Jessie BC, Sun QC, Baumann AK, Amin M, Lim SD, Fernan-dez-Golarz C, Lyles RH, Brown MD, Marshall FF, Petros JA. North American white mitochondrial haplogroups in prostate and renal cancer. J Urol 2006;175: 
468-473.

Brandon M, Baldi P, Wallace DC. Mitochondrial mutations in cancer. Oncogene 2006; 25: 4647-4662.

Burnichon N, Brière JJ, Libé R, Vescovo L, Rivière J, Tissier F, Jouanno E, Jeunemaitre X, Bénit P, Tzagoloff A, Rustin P, Bertherat J, Favier J, Gimenez-Roqueplo AP. SDHA is a tumor suppressor gene causing paraganglioma. Hum Mol Genet 2010; 19: 3011-3020.

Cano D, Gomez CF, Ospina N, Cajigas JA, Groot H, Andrade RE. Torres MM: Mitochondrial DNA haplogroups and susceptibility to prostate cancer in a Colombian population. ISRN Oncol 2014: 530675.

Canter JA, Kallianpur AR, Parl FF, Millikan RC. Mitochondrial DNA G10398A polymorphism and invasive breast cancer in African-American women. Cancer Res 2005; 65: 8028-8033.

Chinnery PF, Samuels DC, Elson J, Turnbull DM. Lancet 2002; 360: 1323-1325.

Coller HA, Khrapko K, Bodyak ND, Nekhaeva E, Herrero-Jimenez P, Thilly WG. High frequency of homoplasmic mitochondrial DNA mutations in human tumors can be explained without selection. Nat Genet 2001; 28: 147-150.

Cook CC, Kim A, Terao S, Gotoh A, Higuchi M. Consumption of oxygen: a mitochondrial generated progression signal of advanced cancer. Cell Death Dis 2012; 3: e258.

Copeland WC, Wachsman JT, Johnson FM, Penta JS. Mitochondrial DNA alterations in cancer. Cancer Invest 2002; 20: 557-569.

Coskun PE, Beal MF, Wallace DC. Alzheimer's brains harbor somatic mtDNA control-region mutations that suppress mitochondrial transcription and replication. Proc Natl Acad Sci USA 2004; 101: 10726-10731.

Czarnecka AM, Golik P, Bartnik E. Mitochondrial DNA mutations in human neoplasia. J Appl Genet 2006; 47: 67-78.

Czarnecka M and Bartnik E. Mitochondrial DNA mutations in tumors. In: Cellular Respiration and Carcinogenesis. Apte SP and Sarangarajan R (eds). Humana Press, New York. 2009; pp: 119-130.

Czarnecka AM, Krawczyk T, Zdrożny M, Lubiński J, Arnold RS, Kukwa W, Scińska A, Golik P, Bartnik E, Petros JA. Mitochondrial NADH-dehydrogenase subunit3(ND3) polymorphism (A10398G) and sporadic breast cancer in Poland. Breast Cancer Res Treat 2010; 121: 511-518.

Czarnecka AM, Krawczyk T, Plak K, Klemba A, Zdrozny M, Arnold RS, Kofler B, Golik P, Szybinska A, Lubinski J, Mossakowska M, Bartnik E, Petros JA. Mitochondrial genotype and breast cancer predisposition. Oncol Rep 2010; 24: 15211534.

Czarnecka AM and Bartnik E. The role of the mitochondrial genome in ageing and carcinogenesis. J Aging Res 2011; 136435.

Darvishi K, Sharma S, Bhat AK, Rai E, Bamezai RN. Mitochondrial DNA G10398A polymorphism imparts maternal Haplogroup N a risk for breast and esophageal cancer. Cancer Lett 2007; 249: 249-255.

Dasgupta S, Hoque MO, Upadhyay S, Sidransky D. Mitochondrial cytochrome B gene mutation promotes tumor growth in bladder cancer. Cancer Res 2008; 68: 700-706.

Dasgupta S, Hoque MO, Upadhyay S, Sidransky D. Forced cytochrome B gene mutation expression induces mitochondrial proliferation and prevents apoptosis in human uroepithelial SV-HUC -1 cells. Int J Cancer 2009; 125 : $2829-2835$.

Delsite RL, Rasmussen LJ, Rasmussen AK, Kalen A, Goswami PC, Singh KK. Mitochondrial impairment is accompanied by impaired oxidative DNA repair in the nucleus. Mutagenesis 2003; 18: 497-503. 
Desouki MM, Kulawiec M, Bansal S, Das GM, Singh KK. Crosstalk between mitochondria and superoxide generating NADPH oxidase in breast and ovarian tumors. Cancer Biol Ther 2005; 4: 1367-1373

Dimauro S and Davidzon G. Mitochondrial DNA and disease. Ann Med 2005; 37: 222-232.

Downward J. Targeting RAS signaling pathways in cancer therapy. Nat Rev Cancer 2003; 3: 11-22.

Egea PF, Stroud RM, Walter P: Targeting proteins to membranes: Structure of the signal recognition particle. Curr Opin Struct Biol 2005; 15: 213-220.

Elmore S. Apoptosis: a review of programmed cell death. Toxicol Pathol 2007; 35: 495-516.

Fang H, Shen L, Chen T, He J, Ding Z, Wei J, Qu J, Chen G, Lu J, Bai Y. Cancer type-specific modulation of mitochondrial haplogroups in breast, colorectal and thyroid cancer. BMC Cancer 2010: 421.

Fernández-Silva P, Enriquez JA, Montoya J. Replication and transcription of mammalian mitochondrial DNA. Exp Physiol 2003; 88: 41-56.

Fliss MS, Usadel H, Caballero OL, Wu L, Buta MR, Eleff SM, Jen J, Sidransky D: Facile detection of mitochondrial DNA mutations in tumors and bodily fluids. Science 2000; 287: 2017- 2019.

Formentini L, Martinez-Reyes I, Cuezva JM. The mitochondrial bioenergetic capacity of carcinomas. IUBMB Life 2010; 62: 554-560.

Gaude E and Frezza, C. Defects in mitochondrial metabolism and cancer. Cancer Metab 2014; 2: 10.

Giompazolias E and Tait SW. Mitochondria and the hallmarks of cancer. FEBS J 2016 283: 803-814.

Guaragnella N, Giannattasio S, Moro L. Mitochondrial dysfunction in cancer chemoresistance. BioChem Pharmacol 2014; 92: 62-72.

Guerra F, Guaragnella N, Arbini AA, Bucci C, Giannattasio S, Moro L. Mitochondrial Dysfunction: A Novel Potential Driver of Epithelial-to-Mesenchymal Transition in Cancer. Front Oncol 2017; 7: 295.

Guha M, Fang JK, Monks R, Birnbaum MJ, Avadhani NG. Activation of Akt is essential for the propagation of mitochondrial respiratory stress signaling and activation of the transcriptional coactivator heterogeneous ribonucleoprotein A2. Mol Biol Cell 2010a; 21: 3578-3589.

Guo J, Zheng L, Liu W, Wang X, Wang Z, Wang Z, French AJ, Kang D, Chen L, Thibodeau SN, Liu W. Frequent truncating mutation of TFAM induces mitochondrial DNA depletion and apoptotic resistance in microsatellite- unstable colorectal cancer. Cancer Res 2011; 71: 2978-2987.

Hanahan D and Weinberg RA. Hallmarks of cancer: The next generation. Cell 2011; 144: 646-674.

He Y, Wu J, Dressman DC, Iacobuzio-Donahue C, Markowitz SD, Velculescu VE, Diaz Jr LA, Kinzler KW, Vogelstein B, Papadopoulos N. Heteroplasmic mitochondrial DNA mutations in normal and tumour cells. Nature 2010; 464: 610-614.

Higuchi M, Aggarwal BB, Yeh ET. Activation of CPP32-like protease in tumor necrosis factor induced apoptosis is dependent on mitochondrial function. J Clin Invest 1997; 99: 1751-1758.

Higuchi M, Kudo T, Suzuki S, Evans TT, Sasaki R, Wada Y,Shirakawa T, Sawyer JR, Gotoh A. Mitochondrial DNA determines androgen dependence in prostate cancer cell lines. Oncogene 2006; 25: 1437-1445.

Higuchi M, Manna SK, Sasaki R, Aggarwal BB. Regulation of the Activation of Nuclear Factor kappaB by Mitochondrial Respiratory Function: Evidence for the Reactive Oxygen Species Dependent and -Independent Pathways. Antioxid Redox Signal 
2002; 4: 945-955.

Hofhaus G and Gattermann N. Mitochondria harbouring mutant mtDNA-a cuckoo in the nest? Biol Chem 1999; 380: 871877.

Horton TM, Petros JA, Heddi A, Shoffner J, Kaufman AE, Graham Jr SD, Gramlich T, Wallace DC. Novel mitochondrial DNA deletion found in a renal cell carcinoma. Gen Chrom Cancer 1996; 15: 95-101.

Huanzheng Li, Jesse Slone, Lin Fei, Taosheng Huang. Mitochondrial DNA Variants and Common Diseases: A Mathematical Model for the Diversity of Age-Related mtDNA Mutations. Cells 2019; 8: 608.

Hu SP, Du JP, Li DR, Yao YG. Mitochondrial DNA haplogroup confers genetic susceptibility to nasopharyngeal carcinoma in Chaoshanese from Guangdong, China. PLoS One 2014; 9: e87795.

Iommarini L, Kurelac I, Capristo M, Calvaruso MA, Giorgio V, Bergamini C, GhelliA, Nanni P, Giovanni CDe, Carelli V, Fato R, Lollini PL, Rugolo M, Gasparre G, Porcelli AM. Different mtDNA mutations modify tumor progression in dependence of the degree of respiratory complex I impairment. Hum Mol Genet 2014; 23: 1453-1466.

Ishikawa K, Takenaga K, Akimoto M, Koshikawa N, Yamaguchi A, Imanishi H, Nakada K, Honma Y, Hayashi JI. ROSgenerating mitochondrial DNA mutations can regulate tumor cell metastasis. Science 2008; 320: 661-664.

Yeh JJ, Lunetta KL, van Orsouw NJ, Moore Jr FD, Mutter GL, Vijg J,Dahia PLM, Eng C. Somatic mitochondrial DNA (mtDNA) mutations in papillary thyroid carcinomas and differential mtDNA sequence variants in cases with thyroid tumours. Oncogene 2000; 19: 2060-2066.

Jiang J, Zhao JH, Wang XL, Di JI, Liu ZB, Li GY, Wang MZ, Li Y, Chen R, Ge RL. Analysis of mitochondrial DNA inTibetan gastric cancer patients at high altitude. Mol Clin Oncol 2015; 3: 875-879.

Ju YS, Alexandrov LB, Gerstung M, Martincorena I, Nik-Zainal S, Ramakrishna M, Davies HR, Papa-emmanuil E, Gundem G, Shlien A, Bolli N, Behjati S, Tarpey PS, Nangalia J, Massie CE, Butler AP, Teague JW. Origins and functional consequences of somatic mitochondrial DNA mutations in human cancer. Elife 2014; 3: 02935.

Kamp WM, Wang PY, Hwang PM. TP53 mutation, mitochondria and cancer. Curr Opin Genet Dev 2016; 38: 16-22.

Khrapko K, Coller HA, Andre PC, Li XC, Hanekamp JS, Tilly WG. Mitochondrial mutational spectra in human cells and tissues. Proc Natl Acad Sci USA 1997; 94: 13798-13803.

Kirches E, Krause G, Warich-Kirches M, Weis S, Schneider T, Meyer-Puttlitz B, Mawrin C, Dietzmann K. High frequency of mitochondrial DNA mutations in glioblastoma multiforme identified by direct sequence comparison to blood samples. Int $J$ Cancer 2001; 93: 534-538.

Kirches E. Mitochondrial and nuclear genes of mitochondrial components in cancer. Curr Genomics 2009; 10: $281-293$.

Kloss-Brandstatter A, Weissensteiner H, Erhart G, Schafer G, Forer L, Schonherr S, Pacher D, Seifarth C, StöcklA, Fendt L, Sottsas I, Klocker H, Huck CW, Rasse M, Kronenberg F, Kloss FR.Validation of next-generation sequencing of entire mitochondrial genomes and the diversity of mitochondrial DNA mutations in oral squamous cell carcinoma. PLoS One 2015; 10: e0135643.

Kumimoto Y, Yamane Y Nishimoto H, Fukami M, Shinoda S, Hatooka K, Ishizaki K. Frequent somatic mutations of mitochondrial DNA in esophageal squamous cell carcinoma. Int J Cancer 2004; 108: 228-231.

Kuo SJ, Chen M, Ma GC, Chen ST, Chang SP, Lin WY, Chen YC, Lee TH, Lin TT, Liu CS. Number of somatic mutations in the mitochondrial D-loop region indicates poor prognosis in breast cancer, independent of TP53 mutation. Cancer Genet Cytogenet 2010; 201: 94-101. 
Kurelac I, MacKay A, Lambros MB, Di Cesare E, Cenacchi G, Ceccarelli C, Morra I, Melcarne A, Morandi L, Calabrese FM, Attimonelli M, Tallini G, Reis-Filho JS, Gasparre G. Somatic complex I disruptive mitochondrial DNA mutations are modifiers of tumorigenesis that correlate with low genomic instability in pituitary adenomas. Hum Mol Genet 2013; 22: $226-238$.

Kurtz A, Lueth M, Kluwe L, Zhang T, Foster R, Mautner VF, Hartmann M, Tan DJ, Martuza RL, Friedrich RE, Driever PH, Wong LJ C. Somatic Mitochondrial DNA Mutations in Neurofibromatosis Type 1-Associated Tumors. Mol Cancer Res 2004; 2: 433-441.

Lam ET, Bracci PM, Holly EA, Chu C, Poon A, Wan E, White K, Kwok PY, Pawlikowska L, Tranah GJ. Mitochondrial DNA sequence variation and risk of pancreatic cancer. Cancer Res 2012; 72: 686-695.

Larman TC, DePalma SR, Hadjipanayis AG, Protopopov A, Zhang J, Gabriel SB, Chin L, Seidman CE, Kucherlapati R and Seidman JG; Cancer Genome Atlas Research Network: Spectrum of somatic mitochondrial mutations in five cancers. Proc Natl Acad Sci USA 2012; 109: 14087-14091.

Lee WTY, Cain JE, Cuddihy A, Johnson J, Dickinson A, Yeung K-Y, Kumar B, Johns TG, Watkins DN, Spencer A, John JCSt. Mitochondrial DNA plasticity is an essential inducer of tumorigenesis. Cell Death Discovery 2016; 2: 1-11.

Lee HC, Li SH, Lin JC, Wu CC, Yeh DC, Wei YH. Somatic mutations in the D-loop and decrease in the copy number of mitochondrial DNA in human hepatocellular carcinoma. Mutat Res 2004; 547: 71-78.

Lee HC, Yin PH, Lin JC, Wu CC, Chen CY, Wu CW, Chi CW, Tam TN, Wei YH. Mitochondrial genome instability and mtDNA depletion in human cancers. Ann N Y Acad Sci 2005; 1042: 109-122.

Lehtonen R, Husgafvel-Pursiainen K, Isola J, Järvinen H, Koivisto P, Kiuru M, Vanharanta S, Sjöberg J, Aaltonen LM, Aittomaki K, Arola J, Butzow R, Eng C. Biallelic inactivation of fumarate hydratase (FH) occurs in nonsyndromic uterine leiomyomas but is rare in other tumors. Am J Pathol 2004; 164: 17-22.

Li Y, Beckman KB, Caberto C, Kazma R, Lum-Jones A, Haiman CA, Le Marchand L, Stram DO, Saxena R, Cheng I: Association of genes, pathways, and haplogroups of the mitochondrial genome with the risk of colorectal cancer: The multiethnic Cohort. PLoS One 2015; 10: e0136796.

Liang BC and Hays L. Mitochondrial DNA copy number changes in human gliomas. Cancer Lett 1996; 105: $167-173$.

Linkowska K, Jawien A, Marszalek A, Malyarchuk BA, Tonska K, Bartnik E, Skonieczna K, Grzybowski T. Mitochondrial DNA polymerase gamma mutations and their implications in mtDNA alterations in colorectal cancer. Ann Hum Genet 2015; 79: 320-328.

Liou CW, Lin TK, Chen JB, Tiao MM, Weng SW, Chen SD, Chuang YC, Chuang JH, Wang PW. Association between a common mitochondrial DNA D-loop polycytosine variant and alteration of mitochondrial copy number in human peripheral blood cells. J Med Genet 2010; 47: 723-728.

Liu VW, Wang Y, Yang HJ, Tsang PCK,Ng TY, Wong L-C, Nagley P, Ngan HYS. Mitochondrial DNA variant 16189T $>$ C is associated with susceptibility to endometrial cancer. Hum Mutat 2003; 22: 173-174.

Liu VW, Shi HH, Cheung AN, Chiu PM,Leung TW, Nagley P, Wong LC, Ngan HY. High incidence of somatic mitochondrial DNA mutations in human ovarian carcinomas. Cancer Res 2001; 61: 5998-6001.

Lynch SM, Weinstein SJ, Virtamo J, Lan Q, Liu CS, Cheng WL, Rothman N, Albanes D, Stolzenberg-. Solomon RZ. Mitochondrial DNA copy number and pancreatic cancer in the alpha-tocopherol beta-carotene cancer prevention study. Cancer Prev Res (Phila) 2011; 4: 1912-1919.

Mancuso M, Filosto M, Choub A, Tentorio M, Broglio L, Padovani A, Siciliano G. Mitochondrial DNA-related disorders. Biosci Rep 2007; 27: 31-37. 
Máximo V, Soares P, Lima J, Cameselle-Teijeiro J, Manuel Sobrinho-Simões M. Mitochondrial DNA somatic mutations (point mutations and large deletions) and mitochondrial DNA variants in human thyroid pathology: a study with emphasis on Hürthle cell tumors. Am J Pathol 2002; 160: 1857-1865.

Masuda S, Kadowaki T, Kumaki N, Tang X, Tokuda Y, Yoshimura S, Takekoshi S, Osamura RY. Analysis of gene alterations of mitochondrial DNA D-loop regions to determine breast cancer clonality. Br J Cancer 2012; 107: 2016-2023.

Modica-Napolitano JS and Singh K. Mitochondria as targets for detection and treatment of cancer. Expert Rev Mol Med 2002; 4: 1-19.

Modica-Napolitano JS, Kulawiec M, Singh KK: Mitochondria and human cancer. Curr Mol Med 2007; 7: 121-131.

Modica-Napolitano JS and Singh KK. Mitochondrial dysfunction in cancer. Mitochondrion 2004; 4: 755-762.

McMahon S and La Framboise T. Mutational patterns in the breast cancer mitochondrial genome, with clinical correlates. Carcinogenesis 2014; 35: 1046-1054.

Naito Akihiro, Mizumachi Takatsugu, Wang Mian, Xie Cheng-hui, Evans T Teresa, Thomas J Kelly, Masahiro Higuchi. Progressive tumor features accompany epithelial-mesenchymal transition induced in mitochondrial DNA depleted cells. Cancer Sci 2008; 99: 1584-1588.

Neupert W and Herrmann JM: Translocation of proteins into mitochondria. Annu Rev Biochem 2007; 76: 723-749.

Nomoto S, Yamashita K, Koshikawa K, Nakao A, Sidransky D. Mitochondrial D-loop Mutations As Clonal Markers in Multicentric Hepatocellular Carcinoma and Plasma. Clin Cancer Res 2002; 8: 481-487.

Nguyen AD, McDonald JG, Bruick RK, DeBose-Boyd RA. Hypoxia stimulates degradation of 3- hydroxy-3-methylglutarylcoenzyme A reductase through accumulation of lanosterol and hypoxiainducible factor-mediated induction of insigs. $J$ Biol Chem 2007; 282: 27436-27446.

Nicholls TJ and Minczuk M. In D-loop: 40 years of mitochondrial 7S DNA. Exp Gerontol 2014; 56: 175-181.

Nishimura G, Proske RJ, Doyama H, Higuchi M. Regulation of apoptosis by respiration: cytochrome c release by respiratory substrates. FEBS Lett 2001; 505: 399-404.

Okochi O, Hibi K, Uemura T, Inoue S, Takeda S, Kaneko T. Detection of mitochondrial DNA alterations in the serum of hepatocellular carcinoma patients. Clin Cancer Res 2002; 8: 2875-2878.

Pagliarini DJ, Calvo SE, Chang B, Sheth SA, Vafai SB, Ong SE, Walford GA,Sugiana C,Boneh A, Chen WK, Hill DE, Vidal M, Evans JG, Thorburn DR, Carr SA, Mootha VK. A mitochondrial protein compendium elucidates complex I disease biology. Cell 2008; 134: 112-123.

Park SY, Chang I, Kim JY, Kang SW, Park SH, Singh K, Lee MS. Resistance of mitochondrial DNA depleted cells against cell death: Role of mitochondrial superoxide dismutase. J Biol Chem 2004; 279: 7512-7520.

Parker SJ and Metallo CM. Metabolic consequences of oncogenic IDH mutations. Pharmacol Ther 2015; 152: 54-62.

Pelicano H, Xu RH, Du M, Feng L, Sasaki R, Carew JS,Hu Y,Ramdas L, Hu L,Keating MJ,Zhang W, Plunkett W, Huang P. Mitochondrial respiration defects in cancer cells cause activation of Akt survival pathway through a redox-mediated mechanism. J Cell Biol 2006; 175: 913-923.

Peng TI, Yu PR, Chen JY, Wang HL, Wu HY, Wei YH, Jou MJ. Visualizing common deletion of mitochondrial DNAaugmented mitochondrial reactive oxygen species generation and apoptosis upon oxidative stress. Biochim Biophys Acta 2006; 1762: 241-255. 
Petros JA, Baumann AK, Ruiz-Pesini E, Amin MB, Sun CQ, Hall J, Lim S, Issa MM, Flanders WD, Hosseini SH, Marshall FF, Wallace DC. mtDNA mutations increase tumorigenicity in prostate cancer. Proc Natl Acad Sci USA 2005; 102: 719-724.

Polyak K, Li Y, Zhu H, Lengauer C, Willson JKV, Markowitz SD, Trush MA,Kinzler KW, Vogelstein B. Somatic mutations of the mitochondrial genome in human colorectal tumours. Nat Genet 1998; 20: 291-293.

Poynter JN, Richardson M, Langer E, Hooten AJ, Roesler M, Hirsch B, Nguyen PL, Cioc A, Warlick E, Ross JA. Association between mitochondrial DNA haplogroup and myelodysplastic syndromes. Gen Chrom Cancer 2016; 55: 688-693.

Qu F, Liu X, Zhou F, Yang H, Bao G, He X and Xing J. Association between mitochondrial DNA content in leukocytes and colorectal cancer risk. Cancer 2011; 117: 3148-3155.

Rasmussen AK, Chatterjee A, Rasmussen LJ, Singh KK. Mitochondria-mediated nuclear mutator phenotype in Saccharomyces cerevisiae. Nucleic Acids Res 2003; 31: 3909-3917.

Reid R. Can migratory mitochondria DNA activate oncogenes? Trends Biochem Sci 1983; 8: 190-191.

Reitman ZJ, Jin G, Karoly ED, Spasojevic I, Yang J, Kinzler KW, He Y, Bigner DD, Vogelstein B, Yan H. Profling the effects of isocitrate dehydrogenase 1 and 2 mutations on the cellular metabolome. Proc Natl Acad Sci USA 2011; 108: 3270-3275.

Reznik E, Miller ML, Şenbabaoğlu Y, Riaz N, Sarungbam J, Tickoo SK, Al-Ahmadie HA, Lee W, Seshan VE, Hakimi AA, Sander C. Mitochondrial DNA copy number variation across human cancers. Elife 2016; 5: e10769.

Rogalinska M. The role of mitochondria in cancer induction, progression and changes in metabolism. Mini Rev Med Chem 2016; 16: 524-530.

Salgado J, Honorato B, Garcia-Foncillas J. Review: mitochondrial defects in breast cancer. Clin Med Oncol 2008; 2: 199207.

Savagner F, Franc B, Guyetant S, Rodien P, Reynier P, Malthiery Y. Defective mitochondrial ATP synthesis in oxyphilic thyroid tumors. J Clin Endocrinol Metab 2001; 86: 4920-4925.

Senf D and Ronai ZA. Regulators of mitochondrial dynamics in cancer. Curr Opin Cell Biol 2016; 39: 43-52.

Shay JW and Werbin H. New evidence for the insertion of mitochondrial DNA into the human genome: significance for cancer and aging. Mutat Res 1992; 275: 227-235.

Shidara Y, Yamagata K, Kanamori T, Nakano K, Kwong JQ, Manfredi G,Oda H, Ohta S. Positive contribution of pathogenic mutations in the mitochondrial genome to the promotion of cancer by prevention from apoptosis. Cancer Res 2005; 65: 16551663.

Singh KK. Mitochondrial damage checkpoint in apoptosis and genome stability. FEMS Yeast Res 2004; 2: 127-132.

Singh KK and Kulawiec M. Mitochondrial DNA polymorphism and risk of cancer. Methods Mol Biol 2009; 471: 291-303, 2009.

Singh B, Owens KM, Bajpai P, Desouki MM, Srinivasasainagendra V, Tiwari HK, Singh KK Mitochondrial DNA polymerase POLG1 disease mutations and germline variants promote tumorigenic properties. PLoS One 2015; 10 : e0139846.

Song BL, Javitt NB, DeBose-Boyd RA. Insig-mediated degradation of HMG CoA reductase stimulated by lanosterol, an intermediate in the synthesis of cholesterol. Cell Metab 2005; 1: 179-189.

Stefano GB and Kream RM. Cancer: mitochondrial origins. Med Sci Monitor 2015; 21: 3736-3739.

Stefano GB and Kream RM. Mitochondrial DNA heteroplasmy in human health and disease. Biomed Rep 2016; 4: 259- 
262.

Stewart JB and Chinnery PF. The dynamics of mitochondrial DNA heteroplasmy: Implications for human health and disease. Nat Rev Genet 2015; 16: 530-542.

Stoneking M. Hypervariable sites in the mtDNA control region are mutational hotspots. Am J Hum Genet 2000; 67: 10291032.

Su X, Wang W, Ruan G, Liang M, Zheng J, Chen Y, Wu H, Fahey TJ III, Guan M and Teng L: A comprehensive characterization of mitochondrial genome in papillary thyroid cancer. Int J Mol Sci 2016; 17: 1594.

Sui G, Zhou S, Wang J, Canto M,Lee EE, Eshleman JR, Montgomery EA, Sidransky D, Califano JA, Maitra A. Mitochondrial DNA mutations in preneoplastic lesions of the gastrointestinal tract: a biomarker for the early detection of cancer. Mol Cancer 2006; $5: 73$.

Suzuki S, Naito A, Asano T, Evans TT, Reddy SA, Higuchi M. Constitutive Activation of AKT Pathway Inhibits TNFinduced Apoptosis in Mitochondrial DNA-Deficient human myelogenous leukemia ML-1a. Cancer Lett 2008; 268: 31-37.

van Gisbergen MW, Voets AM, Starmans MH, de Coo IF, Yadak R, Hoffmann RF, Boutros PC, Smeets HJ, Dubois L and Lambin P: How do changes in the mtDNA and mitochondrial dysfunction influence cancer and cancer therapy? Challenges, opportunities and models. Mutat Res Rev Mutat Res 2015; 764: 16-30.

van Oven M. PhyloTree Build 17: growing the human mitochondrial DNA tree. Forensic Sci Int Genet Suppl Ser 2015; 5: e392-394.

Vander Heiden MG, Cantley LC, Thompson CB. Understanding the Warburg effect: the metabolic requirements of cell proliferation. Science 2009; 324: 1029-1033.

Vanharanta S, Buchta M, McWhinney SR, Virta SK, Peczkowska M, Morrison CD, Lehtonen R,Januszewicz A, Järvinen H,Juhola M,Mecklin J-P, Pukkala E, Herva R, Kiuru M, Nupponen NN, Aaltonen LA, Neumann HPH, Eng C. Early-onset renal cell carcinoma as a novel extraparaganglial component of SDHB-associated heritable paraganglioma. Am J Hum Genet 2004;74: 153159.

Verma M, Naviaux RK, Tanaka M, Kumar D, Franceschi C, Singh KK. Meeting report: Mitochondrial DNA and cancer epidemiology. Cancer Res 2007;67: 437-439.

Vyas S, Zaganjor E, Haigis MC. Mitochondria and cancer. Cell 2016; 166: 555-566.

Wai T, Teoli D, Shoubridge EA. The mitochondrial DNA genetic bottleneck results from replication of a subpopulation of genomes. Nat Genet 2008; 40: 1484-1488.

Wallace DC, Chalkia D. Mitochondrial DNA genetics and the heteroplasmy conundrum in evolution and disease. Cold Spring Harb Perspect Biol 2013 5: a021220.

Wallace DC. A mitochondrial paradigm of metabolic and degenerative diseases, aging, and cancer: a dawn for evolutionary medicine. Annu Rev Genet 2005; 39: 359-407.

Wang Y, Liu VW, Xue WC, Tsang PC, Cheung AN, Ngan HY. The increase of mitochondrial DNA content in endometrial adenocarcinoma cells: A quantitative study using laser-captured microdissected tissues. Gynecol Oncol 2005; 98: 104-110.

Warburg O. On the origin of cancer cells. Science 1956; 123: 309-314.

Warburg O. Metabolism of Tumors. Arnold Constable; London, UK: 1930

Ward Patrick S and Thompson Craig B. Metabolic Reprogramming: A Cancer Hallmark Even Warburg Did Not 
Anticipate. Cancer Cell 2012; 21: 297-308.

Wei Guo, Denghua Yang, Hongbo Xu, Yang Zhang, Junwei Huang, Zheng Yang, Xiaohong Chen, Zhigang Huang. Mutations in the D-loop region and increased copy number of mitochondrial DNA in human laryngeal squamous cell carcinoma. Molecul Biol Rep 2013;40: 13-20.

Weissensteiner H, Pacher D, Kloss-Brandstatter A, Forer L, Specht G, Bandelt HJ, Kronenberg F, Salas A, Schönherr S. HaploGrep 2: mitochondrial haplogroup classification in the era of high-throughput sequencing. Nucleic Acids Res 2016; 44: W58-W63.

Wu CW, Yin PH, Hung WY, Li AF, Li SH, Chi CW, Wei Y-H, Lee H-C. Mitochondrial DNA mutations and mitochondrial DNA depletion in gastric cancer. Gen Chrom Cancer 2005; 44: 19-28.

Wu W and Zhao S. Metabolic changes in cancer: Beyond the Warburg effect. Acta Biochim Biophys Sin (Shanghai) 2013; 45: 18-26.

Xie C, Naito A, Mizumachi T, Evans TT, Douglas MG, Cooney CA,Fan C-Y, Higuchi M. Mitochondrial regulation of Cancer Associated Nuclear DNA Methylation. Biochem Biophys Res Commun 2007; 364: 656-661.

Yakes FM and Van Houten B. Mitochondrial DNA damage is more extensive and persists longer than nuclear DNA damage in human cells following oxidative stress. Proc Natl Acad Sci USA 1997; 94: 514-519.

Yu FY, Xu Q, Wu DD, Lau AT, Xu YM. The Prognostic and Clinicopathological roles of Sirtuin-3 in various cancers. PLoS One 2016; 11: e0159801.

Yu M, Shi Y, Zhang F, Zhou Y, Yang Y, Wei X, Zhang L, Niu R. Sequence variations of mitochon drial DNA D-loop region are highly frequent events in familial breast cancer. J Biomed Sci 2008; 15: 535-543.

Zhang J, Asin-Cayuela J, Fish J, Michikawa Y, Bonafe M, Olivieri F, Passarino G, De Benedictis G, Franceschi C, Attardi G. Strikingly higher frequency in centenarians and twins of mtDNA mutation causing remodeling of replication origin in leukocytes. Proc Natl Acad Sci USA 2003; 100: 1116-1121.

Zhang H, Mizumachi T, Carcel-Trullols J, Li L, Naito A, Spencer HJ, Spring PM, Smoller BR, Watson AJ, Margison GP. Targeting human 8-oxoguanine DNA glycosylase (hOGG1) to mitochondria enhances cisplatin cytotoxicity in hepatoma cells. Carcinogenesis 2007; 28: 1629-1637.

Zhang H, Xie C, Spencer HJ, Zuo C, Higuchi M, Ranganathan G, Kern PA,Chou MW, Huang Q,,Szczesny B, Mitra S, Watson AJ, Margison GP, Fan C-Y. Obesity and hepatosteatosis in mice with enhanced oxidative DNA damage processing in mitochondria. Am J Pathol 2011; 178: 1715-1727.

Zhu W, Qin W, Bradley P, Wessel A, Puckett CL, Sauter ER. Mitochondrial DNA mutations in breast cancer tissue and in matched nipple aspirate fluid. Carcinogenesis 2005; 26: 145-152.

Zong WX, Rabinowitz JD, White E. Mitochondria and cancer. Mol Cell 2016; 61: 667-676. 